\title{
Assessment of quality in specific fractions of Large White Yorkshire boar semen
}

\author{
K. G. Ambily ${ }^{1 *}$, Malati Naik², Hiron M. Harshan ${ }^{3}$, C. Jayakumar ${ }^{4}$, \\ M. P. Unnikrishnan ${ }^{5}$ and A. P. Usha ${ }^{6}$ \\ Department of Animal Reproduction, Gynaecology and Obstetrics, \\ College of Veterinary and Animal Sciences, Mannuthy, Thrissur-680651, Kerala. \\ Kerala Veterinary and Animal Sciences University, India.
}

Citation: Ambily, K. G., Naik, M., Harshan, H. M., Jayakumar, C., Unnikrishnan, M.P. and Usha A.P. 2021. Assesment of quality in specific fractions of Large White Yorkshire boar semen. J. Vet. Anim. Sci. 52(2): 155-160. DOI: https://doi.org/10.51966/jvas.2021.52.2.155-160

Received: 04.01.2021

Accepted: 01.03.2021

Published: 01.06.2021

\begin{abstract}
Boar semen is voluminous and ejaculated as jets or fractions of pre-sperm, sperm rich (SRF) and post-sperm rich fractions. Recent studies have reported more resilient characteristics of sperm in initial portions of SRF towards cold shock and cryopreservation. The present study was conducted to assess the quality of specific fractions of SRF, namely, first $10 \mathrm{~mL}$ of SRF (F1) and rest of SRF (F2) in Large white Yorkshire (LWY) boar semen. Ejaculates were collected using gloved-hand technique and were subjected to quality assessments of volume, $\mathrm{pH}$, sperm progressive motility, concentration, plasma membrane integrity, abnormality, acrosome integrity and sperm membrane cholesterol. Upon statistical analysis, significant differences were noticed in volume, $\mathrm{pH}$, sperm concentration and sperm membrane cholesterol between fractions of the ejaculate.
\end{abstract}

Keywords: Boar semen, sperm rich fraction, F1, F2

Qualities like better-feed conversion efficiency, early maturity, short generation interval, high fecundity, relatively smaller capital investment and a faster economic return to the farmers makes commercial piggery lucrative to farmers. For a sustainable livestock based industry, genetic enhancement is inevitable, towards which artificial insemination (Al) has played a significant role.

Part of MVSc thesis submitted by the first author to the Kerala Veterinary and Animal Sciences University, Pookode, Wayanad, Kerala

1. *MVSc Scholar and corresponding author, email: ambilykanichattu94@gmail.com., Ph: 8281519522

2. Assistant Professor, Veterinary College, Gadag, Karnataka

3. Assistant Professor

4. Assistant Professor and Head

5. Assistant Professor, Centre for Pig Production and Research, KVASU, Mannuthy

6. Director of Farms and Professor and Head, Centre for Pig Production and Research, KVASU, Mannuthy

Copyright: $@ 2021 \mathrm{~K}$. G. Ambily et al. This is an open access article distributed under the terms of the Creative Commons Attribution 4.0 International License (http://creativecommons.org/licenses/by/4.0/), which permits unrestricted use, distribution, and reproduction in any medium, provided the original author and source are credited. 
The process of cryopreservation has aided in realising the full potential of $\mathrm{Al}$ programmes. Unfortunately, boar semen have not been as resilient as other species like bull, leading to reduced fertility with cryopreserved boar semen and hence lack of popularity of Al. This has affected the breeding and genetic enhancement of the specieshas not been as successful as in other species like bulls. One of the major reasons for poor boar sperm cold shock resistance is its low cholesterol to phospholipid ratio of 0.26 (Parks and Lynch, 1992).

Boar semen is voluminous and ejaculated as jets in broadly three fractions as (i) pre-sperm (ii) the SRF and, (iii) the post-sperm-rich (PSRF) which differ in sperm concentration and proportion of accessory sex gland secretions (Mann and Luwak-Mann, 1981). Recent studies have reported that the sperm fortuitously in F1 were resilient to cooling, freezing and thawing because of its lower bicarbonate level (leading to better sperm membrane cholesterol content) and presence or absence of specific proteins. Hence a study was carried out to assess quality of boar semen fractions (F1 and F2).

\section{Materials and methods}

Fouradult Large White Yorkshire (LWY) boars aged 18-24 months reared at the Centre for Pig Production and Research,KVASU, Mannuthy were used for the study. A total of 66 semen ejaculates were collected using gloved hand technique at twice a week frequency with an interval of three to four days between collections from the same boar.Ejaculates were collected as fractions, with the first $10 \mathrm{~mL}$ of SRF being designated as $\mathrm{F} 1$ and the remaining SRF as F2. During the collection, aBuchner funnel was used to separate the gel mass and the semen fractions were transferred to an insulated container for transportation to the laboratory for preliminary evaluation.

The fresh semen collected was evaluated for volume, $\mathrm{pH}$ and concentrationfor 66 ejaculates. However, sperm progressive motility, plasma membrane integrity and abnormality, acrosome integrity and sperm membrane cholesterol content were evaluated for 26 ejaculates. The volume of semen fractions were assessed using a graduated test tube for $\mathrm{F} 1$ and a class A glass cylinder for F2. The $\mathrm{pH}$ of the fractions was assessed using $\mathrm{pH}$ meter (CyberScan pH510, Eutech instruments). For progressive motility assessment, $25 \mu \mathrm{L}$ of $1: 10$ diluted semen (with PBS) was taken on a clean, grease free glass slide, covered with a clean cover slip and examined under $400 x$ magnification of a phase contrast microscope (Olympus, Model: Magnus MLX, India) with bio-therm stage facility maintained at $37^{\circ} \mathrm{C}$. Semen samples with a minimum of 70 per cent sperm progressive motility alone were selected for further analysis. The sperm concentration of each fractions of boar semen ejaculate was determined by using a Neubaeur counting chamber as per Salisbury et al. (1985). The sperm plasma membrane integrity was assessed using SYBR-14/PI (Live/dead ${ }^{\circledR}$ sperm viability kit L7011 Invitrogen, Thermo Fisher Scientific, USA) staining as per De Ambrogi et al. (2006). Sperm fluorescing bright green with SYBR-14 were considered live, while those stained red with PI were considered dead. The morphological abnormalities of sperm in each fraction were assessed using eosin-nigrosin stainingas per Campbell et al. (1953). The sperm acrosome integrity of sperm in each fraction was assessed by Giemsa staining technique as described by Watson (1975). Sperm membrane cholesterol content in each fraction was assessed as per Zlatkis et al. (1953) after harvesting live sperm with Percoll density gradient (Sigma Aldrich, USA). The washed pellets were resuspended in BTS and stored at $-70^{\circ} \mathrm{C}$ until used for estimation of cholesterol. At the time of estimation of cholesterol, pellet of approximately $1000 \times 10^{6}$ sperm were taken in a $15 \mathrm{~mL}$ centrifuge tube and cholesterol was extracted by vortexing with 20 volumes of chloroform: methanol (1:1 V/V) mixture. The mixture was centrifuged at $800 \times$ $\mathrm{g}$ for $5 \mathrm{~min}$ and the supernatant evaporated to dryness under an atmosphere of nitrogen. At the time of estimation, the dried cholesterol was dissolved in one $\mathrm{mL} \mathrm{NP} \mathrm{40:} \mathrm{isopropanol} \mathrm{mixture}$ (ratio 1:9) and its concentration estimated by cholesterol assay kit (Agappe Diagnostics limited, India; Product No: 11403002, Product No: 11403002). 


\section{Results and discussion}

As $\mathrm{F} 1$ was defined as initial $10 \mathrm{~mL}$ of SRF, volume of $\mathrm{F} 2$ alone was analysed statistically. It was observed that F2 volume was significantly higher $(p<0.05)$ for boar 4 (Table 1$)$. Siqueiraet al. (2011) had recorded the volume of $\mathrm{F} 1$ as $10.74 \pm 0.25$ and rest of SRF as 37.37 $\pm 5.73 \mathrm{~mL}$.

The overall mean $\mathrm{pH}$ of both $\mathrm{F} 1$ and F2 were found to be on the alkaline side $(7.22 \pm 0.03$ and $7.41 \pm 0.03)$. The $\mathrm{pH}$ was significantly $(p<0.01)$ lower in F1 than F2 (Table 2).Variations in $\mathrm{pH}$ among different fractions of same ejaculate for animals with a fractionated ejaculation were reported (Frunza et al., 2008). The difference being ascribed to the contributions of accessory gland secretions. The lower $\mathrm{pH}$ of F1could be due to the higher amount of epididymal fluid and lower proportion of bicarbonate containing accessory sex gland secretions (Saravia et al. , 2010).

In the 66 ejaculates studied, overall mean sperm concentration in $\mathrm{F} 1$ and $\mathrm{F} 2$ was $1161.06 \pm 71.01 \times 10 \% / \mathrm{mLand} 706.67 \pm$ $51.75 \times 10^{6} / \mathrm{mL}$, respectively (Table 2 ). The concentration was significantly higher in $\mathrm{F} 1$ when compared to F2 ( $<<0.01)$. This is expected as F1 represents the initial portions of SRF, which has not been diluted with the accessory gland secretions (Saravia, 2008)

The other parameters were assayed for 26 numbers of ejaculates. The overall sperm progressive motility did not differ significantly between F1 and F2 (83.08 \pm 0.96 and 81.35 $\pm 0.94 \%$, respectively, table 3 ). Pena et al. (2003) had also reported a lack of significant difference in progressive motility of sperm in F1 and F2 in Swedish Yorkshire boars. Kumaresan

Table 1. Semen volume (Mean \pm SE) in different fractions of Large white Yorkshire boar fresh semen ejaculate

\begin{tabular}{|c|c|c|c|c|}
\hline $\begin{array}{c}\text { Semen } \\
\text { characteristics }\end{array}$ & Boar & F1 & F2 & $\begin{array}{c}\text { F value (p value) for F2 } \\
\text { Between boars }\end{array}$ \\
\hline \multirow{5}{*}{ Semen Volume $(\mathrm{mL})$} & $1(\mathrm{n}=16)$ & $9.90 \pm 0.18$ & $30.50 \pm 2.76^{\mathrm{a}}$ & \multicolumn{1}{|}{$2.776^{\star}(0.049)$} \\
\cline { 2 - 4 } & $2(\mathrm{n}=17)$ & $10.75 \pm 0.32$ & $30.18 \pm 3.75^{\mathrm{a}}$ & \\
\cline { 2 - 4 } & $3(\mathrm{n}=16)$ & $10.99 \pm 0.52$ & $27.50 \pm 2.75^{\mathrm{a}}$ & \\
\cline { 2 - 4 } & $4(\mathrm{n}=17)$ & $10.96 \pm 0.29$ & $41.68 \pm 5.19^{\mathrm{b}}$ & \\
\cline { 2 - 4 } & Overall $(\mathrm{n}=66)$ & $10.66 \pm 0.17$ & $32.57 \pm 1.98$ & \\
\hline
\end{tabular}

$F 1$ - first $10 \mathrm{~mL}$ of sperm rich fraction; $F 2$ - rest of the sperm rich fraction

ns - non significant; ** - significant at 0.01 level

Table 2. Hydrogen ion concentration and sperm concentration (Mean \pm SE) in different fractions of Large white Yorkshire boar fresh semen ejaculate

\begin{tabular}{|c|c|c|c|c|}
\hline \multirow{2}{*}{$\begin{array}{c}\text { Semen } \\
\text { characteristics }\end{array}$} & Boar & F1 & F2 & $\begin{array}{c}\text { t }- \text { value } \\
\text { (p - value) } \\
\text { Between fractions }\end{array}$ \\
\hline \multirow{4}{*}{$\begin{array}{c}\text { Hydrogen ion } \\
\text { concentration }\end{array}$} & $1(n=16)$ & $7.23 \pm 0.04$ & $7.36 \pm 0.04$ & \multirow{2}{*}{$5.092^{* *}$} \\
\cline { 2 - 4 } & $2(n=17)$ & $7.30 \pm 0.04$ & $7.50 \pm 0.07$ & \multirow{2}{*}{$(0.000)$} \\
\cline { 2 - 4 } & $3(n=16)$ & $7.21 \pm 0.04$ & $7.40 \pm 0.05$ & \\
\cline { 2 - 4 } & Overall $(n=66)$ & $7.22 \pm 0.03$ & $7.41 \pm 0.03$ & \\
\hline \multirow{3}{*}{$\begin{array}{c}\text { Sperm } \\
\text { concentration } \\
\text { (millions/mL) }\end{array}$} & $1(n=16)$ & $1281.88 \pm 153.26$ & $772.50 \pm 108.44$ & \multirow{2}{*}{$5.172^{* *}$} \\
\cline { 2 - 4 } & $2(n=17)$ & $888.24 \pm 107.08$ & $550.00 \pm 75.25$ & \multirow{2}{*}{$(0.000)$} \\
\cline { 2 - 4 } & $3(n=16)$ & $1433.75 \pm 184.64$ & $918.75 \pm 145.45$ & \\
\cline { 2 - 4 } & Overall $(n=66)$ & $1161.06 \pm 71.01$ & $706.67 \pm 51.75$ & \\
\hline
\end{tabular}


Table 3. Sperm progressive motility, Sperm plasma membrane integrity (using SYBR-PI), abnormality and acrosome integrity and sperm cholesterol content (Mean \pm SE)in different fractions of Large white Yorkshire boar fresh semen ejaculate, expressed in per cent

\begin{tabular}{|c|c|c|c|c|}
\hline Semen characteristics & Boar ( $n=3$ each) & $\mathrm{F} 1$ & $\mathrm{~F} 2$ & $\begin{array}{c}\text { t }- \text { value } \\
\text { ( } p \text { - value }) \\
\text { Between groups }\end{array}$ \\
\hline \multirow{5}{*}{$\begin{array}{l}\text { Progressive Motility } \\
\quad \text { (in per cent) }\end{array}$} & $1(n=7)$ & $85.71 \pm 2.02$ & $82.86 \pm 2.14$ & \multirow{5}{*}{$\begin{array}{l}1.284^{\mathrm{ns}} \\
(0.21)\end{array}$} \\
\hline & $2(n=7)$ & $82.14 \pm 1.84$ & $81.43 \pm 2.10$ & \\
\hline & $3(n=6)$ & $85.00 \pm 1.29$ & $83.33 \pm 1.05$ & \\
\hline & $4(n=6)$ & $79.17 \pm 1.54$ & $77.50 \pm 1.12$ & \\
\hline & Overall $(n=26)$ & $83.08 \pm 0.96$ & $81.35 \pm 0.94$ & \\
\hline \multirow{5}{*}{$\begin{array}{c}\text { Plasma membrane } \\
\text { integrity by SYBR14 - PI }\end{array}$} & $1(n=7)$ & $86.81 \pm 2.40$ & $85.86 \pm 2.24$ & \multirow{5}{*}{$\begin{array}{l}0.796^{n s} \\
(0.430)\end{array}$} \\
\hline & $2(n=7)$ & $83.36 \pm 1.20$ & $83.65 \pm 1.74$ & \\
\hline & $3(n=6)$ & $89.02 \pm 1.75$ & $86.93 \pm 1.97$ & \\
\hline & $4(n=6)$ & $84.08 \pm 1.94$ & $82.15 \pm 1.57$ & \\
\hline & Overall $(n=26)$ & $85.76 \pm 1.00$ & $84.66 \pm 0.97$ & \\
\hline \multirow{5}{*}{ Sperm abnormality } & $1(n=7)$ & $4.29 \pm 0.51$ & $5.50 \pm 0.73$ & \multirow{5}{*}{$\begin{array}{l}0.984^{\mathrm{ns}} \\
(0.330)\end{array}$} \\
\hline & $2(n=7)$ & $8.21 \pm 0.26$ & $8.21 \pm 0.82$ & \\
\hline & $3(n=6)$ & $5.83 \pm 1.19$ & $6.17 \pm 1.54$ & \\
\hline & $4(n=6)$ & $7.17 \pm 0.67$ & $8.33 \pm 0.65$ & \\
\hline & Overall $(n=26)$ & $6.37 \pm 0.45$ & $7.04 \pm 0.52$ & \\
\hline \multirow{5}{*}{ Acrosome Integrity } & $1(n=7)$ & $93.36 \pm 0.96$ & $91.07 \pm 1.22$ & \multirow{5}{*}{$\begin{array}{l}1.587^{\mathrm{ns}} \\
(0.120)\end{array}$} \\
\hline & $2(n=7)$ & $89.57 \pm 1.13$ & $88.86 \pm 1.07$ & \\
\hline & $3(n=6)$ & $89.83 \pm 1.31$ & $88.08 \pm 1.56$ & \\
\hline & $4(n=6)$ & $91.50 \pm 1.74$ & $90.08 \pm 1.79$ & \\
\hline & Overall $(n=26)$ & $91.10 \pm 0.68$ & $89.56 \pm 0.70$ & \\
\hline \multirow{5}{*}{$\begin{array}{c}\text { Sperm membrane } \\
\text { cholesterol } \\
\text { ( } \mu \mathrm{g} / \mathrm{billion} \text { sperm) }\end{array}$} & $1(n=7)$ & $114.61 \pm 3.16$ & $99.60 \pm 3.71$ & \multirow{5}{*}{$\begin{array}{l}6.319^{\star *} \\
(0.000)\end{array}$} \\
\hline & $2(n=7)$ & $116.10 \pm 2.13$ & $104.99 \pm 1.80$ & \\
\hline & $3(n=6)$ & $116.13 \pm 3.58$ & $104.81 \pm 3.95$ & \\
\hline & $4(n=6)$ & $129.09 \pm 2.60$ & $105.65 \pm 3.15$ & \\
\hline & Overall $(n=26)$ & $118.71 \pm 1.77$ & $103.65 \pm 1.59$ & \\
\hline
\end{tabular}

F 1 - first $10 \mathrm{~mL}$ of sperm rich fraction

F2 - rest of the sperm rich fraction

ns - non significant, ${ }^{* *}$ - significant at 0.01 level

et al. (2011) used CASA to analyse sperm progressive motility in F1 and F2 of boar semen and found no variation in sperm progressive motility of the two fractions.

The overall sperm plasma membrane integrity in F1 and F2 were not significantly different with values $85.76 \pm 1.00$ and 84.66 \pm 0.97 percent, respectively (table 3 ). SYBR$14 / \mathrm{PI}$ has been advocated for identification of viable sperm in different domestic animals including swine, (Garner and Johnson, 1995). Saravia (2008) could not find any difference in sperm viability between the two fractions.

Similar observations were made with sperm abnormality and acrosome integrity too, as sperm in both F1 and F2, no significant differences could be appreciated (table 3 ). The etiology of sperm abnormality can vary widely, including hereditary causes, improper handling and storage of semen, genetic causes, etc. 
(Cerovsky et al., 2005). Lopez Rodriguez et al. (2012) suggested the importance of an intact acrosome in penetration of the oocyte and thus its role in fertilisation process. Both Wilson (2018) and Shylesh (2019) used the Giemsa staining technique to evaluate sperm acrosome integrity in LWY fresh semen ejaculates and recorded acrosome integrity of $90.63 \pm 1.03$ and $91.81 \pm 0.86$ per cent, respectively.

Though there were no significant differences in sperm parameters except concentration between $\mathrm{F} 1$ and F2, the sperm membrane cholesterol content in $\mathrm{F} 1$ and F2 fractions differed significantly $(p<0.01$, $118.71 \pm 1.77 \mu \mathrm{g} / 10^{9}$ sperm in $\mathrm{F} 1$ and 103.65 $\pm 1.59 \mu \mathrm{g} / 10^{9} \mathrm{sperm}$ in F2). The basis of the higher cholesterol content in $\mathrm{F} 1$ or rather lower cholesterol content in sperm of F2 could be ascribed to the higher bicarbonate in F2 as recorded by Saravia (2008). The epididymal spermatozoa, post-exposure to high bicarbonate levels and specific proteins, undergo phospholipid scrambling at the apical region (Gadella and Harrison, 2002). The scrambling of phospholipids leads to cholesterol relocalization at the sperm head, which precedes cholesterol extraction before capacitation. Leahy and Gadella (2015) suggested the role of bicarbonate and calcium ions in bringing about functional changes in the sperm lateral distribution of cholesterol and its efflux in the presence of albumin and enhanced membrane fluidity. In fresh ejaculates of LWY boar semen, Shylesh (2019) found average sperm cholesterol content of $110.98 \pm 1.64 \mu \mathrm{g} /$ billion sperm, which ranged from 101.13 to $119.36 \mu \mathrm{g} /$ billion sperm.

Thus, there were no apparent changes brought about by the lower levels of sperm membrane cholesterol of F2at fresh semen stage. However, the sperm of F1 might be more resistant to cold shock and stress of cryopreservation because of better cholesterol content. Hence, future cryopreservation studies could focus on utilizing sperm of F1 fraction, which had significantly high concentration (avoiding the need for centrifugation) and higher cholesterol content (thus better cryotolerance).

\section{Acknowledgement}

The authors acknowledge the facilities and funding provided by the Dean, CVAS, Mannuthy and the DAR, KVASU and the facilities received from the Centre for Pig Production and Research, Mannuthy.

\section{References}

Ambrogi, M., Ballester, J., Saravia, F., Caballero, I., Johannisson, A., Wallgren, M., Andersson, M. and Rodriguez-Martinez, H. 2006. Effect of storage in short and long-term commercial semen extenders on the motility, plasma membrane and chromatin integrity of boar spermatozoa. Int. J. Androl. 29: 543-552.

Campbell, R. G., Hancok, J. L. and Rothschild, L. 1953. Counting live and dead bull spermatozoa. J. Exp. Biol. 30: 44.

Cerovsky, J., Frydrychova, S., Lustykova, A. and Rozkot, M. 2005. Changes in boar semen with a high and low level of morphologically abnormal spermatozoa. J. Anim. Sci. 50: 289-299.

Frunza, I., Cernescu, H. and Korodi, G. 2008. Physical and chemical parameters of boar sperm. Lucrariştiintifice Med. Vet. 41: 634-640.

Gadella, B.M. and Harrison, R.A.P. 2002. Capacitation induces cyclic adenosine 3', 5'-monophosphate-dependent, but apoptosis-unrelated, exposure of aminophospholipids at the apical head plasma membrane of boar sperm cells. Biol. Reprod. 67 : 340-350.

Garner, D. L. and Johnson, L. A. 1995. Viability assessment of mammalian sperm using SYBR-14 and propidium iodide. Biol. Reprod. 53: 276-284.

Kumaresan, A., Siqueira, A.P., Hossain, M.S. and Bergqvist, A.S. 2011. Cryopreservationinduced alterations in protein tyrosine phosphorylation of spermatozoa from different portions of the boar ejaculate. Cryobiology: 137-144. 
Leahy, T. and Gadella, B.M., 2015.New insights into the regulation of cholesterol efflux from the sperm membrane.Asian J. Androl.17:561.

López Rodríguez, A., Rijsselaere, T., Vyt, P., Van Soom, A. and Maes, D., 2012.Effect of dilution temperature on boar semen quality.Reprod. Dom. Anim. 47: 63-e66.

Mann, T. and Lutwak-Mann, C. 1981. Male reproductive function and the composition of semen: general consideration in themes and trends in physiology, biochemistry and investigative andrology, Springer Verlag, Berlin. 364 .

Parks, J. E. and Lynch, D. V. 1992. Lipid composition and thermotropic phase behaviour of boar, bull, stallion, and rooster sperm membranes. Cryobiology.29: 255-266.

Pena, F. J., Johannisson, A., Wallgren, M. and Rodriguez Martinez, H. 2003. Assessment of fresh and frozen thawed boar semen using an annexin-v assay: a new method to evaluate sperm membrane integrity. Theriogenology.60: 677-89.

Salisbury, G. W., Van Denmark, N. L. and Lodge, J. R. 1985. Physiology of reproduction and artificial insemination of cattle, 2nd edn, CBS Publishersand Distributors, Shahdara, New Delhi, India. pp. 286328.

Saravia, F. 2008. Cryopreservation of boar semen: impact of the use of specific ejaculate portions, concentrated packaging, and simplified freezing procedures on sperm cryosurvival and potential fertilising capacity. Doctoral thesis, Swedish University of Agricultural Sciences, Uppsala, 63p.

Saravia, F., Wallgren, M. and RodríguezMartínez, H. 2010. Freezing of boar semen can be simplified by handling a specific portion of the ejaculate with a shorter procedure and MiniFlatPack packaging. Anim. Reprod. Sci.117: 279287.

Shylesh, T. 2019. Storage quality of liquid semen ofLarge white yorkshire boar supplemented with cholesterol loaded cyclodextrin. M.V.Sc thesis, Kerala Veterinary and Animal Sciences University, 65p.

Siqueira, A. P., Wallgren, M., Hossain, M. S., Johannisson, A., Sanz, L., Calvete, J. J. and Rodriguez-Martinez, $H$. 2011. Quality of boar spermatozoa from the sperm-peak portion of the ejaculate after simplified freezing in MiniFlatpacks compared to the remaining spermatozoa of the spermrich fraction. Theriogenology. 75: 11751184.

Watson, P. F. 1975. Use of Giemsa stain to detect changes in acrosome of frozen ram spermatozoa. Vet. Rec. 97: 12-15.

Wilson, M. 2018. Freezability of boar semen supplemented with sodium dodecyl sulphate in low or high sperm concentration doses. M.V.Sc thesis, Kerala Veterinary and Animal Sciences University, 98p.

Zlatkis, A., Zak, B. and Boyle, A. J. 1953. A new method for the direct determination of serum cholesterol. J. Lab. Clin. Med. 41: 486-92 